\title{
Driving system of university mathematics practice teaching system II:
}

\section{view of curriculum}

\author{
Xiaobo Liü, a \\ ${ }^{1}$ School of information engineering, Nanjing Xiaozhuang University, Nanjing, China \\ a4487758@qq.com
}

Keywords: university mathematics, practice teaching system, driving system; view of curriculum.

\begin{abstract}
If the college mathematics teaching is divided into practical teaching and theoretical teaching, then the performance of these two kinds of different teaching types, will contains teaching content, the difference of the way, and the transformation of thinking mode. Which is decided that the two aspects are different in nature, such as teachers' view, curriculum view, study view, knowledge view and so on.
\end{abstract}

\section{Introduction}

The basic curriculum view generally takes the quality as the goal of educating people, and the viewpoints that individual quality is the 'general quality' in the specific context of the results of the application, if the 'general quality'has been developed, then the specific quality will naturally be developed. The concept of the curriculum of the elements, the eternal curriculum concept which takes Hutchins as the representative, and the structural curriculum theory which takes Bruner as the representative are the basic curriculum concept of the specific performance. Although different, they are the representative of the Typical Subject Doctrine essentially, which deem that the task of education is to impart knowledge of the eternal truth and certain basic disciplines. In their view, universal elements and experience are more important than personal experience, and they advocate to arrange the course according to the logic of the system of knowledge, pay attention to the integrity of the academic system. In the choice of curriculum content, the attention of the knowledge is not for the future life of the specific knowledge, but to pursue a kind of general ability that have universal significance, the ultimate value of cognitive development to students.

Due to the influence of this kind of subject centered curriculum concept that emphasis on the theoretical knowledge of the system and the development of theoretical thinking. For a long time, college mathematics of China classify courses in accordance with the division of curriculum categories, so that to enable students grasp the system and the complete discipline knowledge system for the goal to focus on teaching, only in the necessary time to assist with the process of practice. Of course, this practice is not self-evident or given the truth of the question, but further to those who have been able to determine the principle of verification, strengthen, so that the theoretical knowledge is more stable. China's current college mathematics teaching materials, basically belong to the one-sided emphasis on mathematical theory and logic system, the application of the problem is reduced to the level of the tool, which deprived students of the ability to abstract problems and solve problems creatively, resulting students in the lack of, and even the loss of consciousness of mathematics application. A series of the status quo such as difficult 
teaching contents, exhaustive requires, theoretically rigorous pursuit, attach importance to theory while despise practice and so on, causes the result that students could not apply mathematical knowledge to solve practical problems. The current textbooks, although revised several times, has not yet to get rid of the traditional education thought generally. The application problems in the textbook compiling is not based on the production of life and solving math problems or the use of mathematics to solve practical problems, but to follow the old teaching materials in the content, lots of exercises in the textbooks cannot stimulate the interest of students.

Most examples and exercises of the probability still touch balls, queue, row number, extraction products and other issues, which are abstract, and the distance from the students' life experience is far away, and the students' application consciousness is not stimulated. In the textbook, the mathematics as a tool to solve the actual problem of consciousness has been diluted, students' thinking ability, practical ability and application ability are so ignored, that they know nothing about cost profit, interest discount, tax payment insurance, savings card password setting, taxi empty driving rate and other basic knowledge of our lives. If we increase the flavor of the times in the examples and exercises, such as newspapers, magazines, television, Internet and other media information, as well as the calculation of interest several input and output, transportation, ecological balance, population control, resources reasonable use and in daily life, shopping, games, some practical problems movement, the life experience of students will be more closely linked with the application of mathematics. Such materials conformed to the spirit of the times are more authentic, while they are easy to stimulate students' interest in learning.

The Postmodernism has been given a deconstruction, criticism and transcendence of modern curriculum theory in the view of complex thinking and broad theory, which focus on the curriculum of "multi-dialogue" and "process", emphasizing the "uncertainty" and "flow" in the view of the characteristics of a curriculum value, that the curriculum is not predesigned, but productive.1975, William Pena, the Postmodernism education theorist of the United States ,Launched the curriculum concept reconstruction movement stressing that the curriculum is a kind of activity, as well as the inner world of travel, and it is the individual in his own experience based on the "run". He regarded course-setting as a kind of complex dialogue process, in order to show the richness of the curriculum, and shows the connected with the participants and the world[1].We call the curriculum model of "practice-oriented " with the generative feature "Practice-oriented curriculum model", which determine the curriculum organization from predesigned to constructed by learners and teachers in practice. Students acquire knowledge through dialogue between action, emphasizing to obtain direct experience from master the practice of knowledge, skills and techniques. So it's obviously that generative practice oriented curriculum concept represents the direction of the future curriculum reform.

In all levels of school education in the curriculum reform, there are appeared a lot of new curriculum concept with China's education reform .But the most popular concept of the curriculum is still subject to the discipline as the center, and it occupy a dominant position especially in higher school discipline of curriculum concept, which adhere to the "subject curriculum" or "curriculum teaching subjects sum" concept in the course of theory, while it put the importance of knowledge to the extreme at the level of value. Besides in the course of practice, standardization and unified dominate the curriculum design and curriculum implementation. ${ }^{[2]}$ The curriculum as the core of the development of education, the reform of the traditional curriculum that just like the previous mode of tinkering is not enough, and the framework must be in accordance with Chinese characteristics of the major framework to reconstruct the university mathematics curriculum system. 
Mathematics teaching should embody the combination of mathematics and modern education technology, reflect the application of mathematics, but also should pay attention to the basic quality of students and the training of mathematical ability.

\section{The construction of the practical characteristics of the university mathematics curriculum system}

The demand for professional construction is the embodiment of the university mathematics curriculum of employment oriented, and to cultivate applied talents as the goal, to meet the requirements of the principle of material, to research professional in depth, it access to professional demand information timely, to build a real-time dynamic module teaching optimization and integration system, as far as possible to choose a professional case to show mathematical applications, so as to pave the way for the subsequent professional courses. In order to reasonably formulate the structure and content of the mathematics curriculum in our university, and highlight the practical characteristics, we should study the professional training objectives, professional competence module and knowledge points. The university mathematics curriculum system structure includes the foundation module, the application module, mainly carries on the theory teaching reform, and includes the special subject module as well, mainly to carry out the computer mathematics experiment, the concrete can be divided into:

The Foundation module. The content of the setting is to ensure that the requirements of the professional to meet the requirements of mathematics, it is the most basic content of the university mathematics, and it's the main content of the calculus as well.

The Application module. The content of the setting can be determined by the professional courses teachers and math teachers, and different application modules are set for different specialties, with main feature of the embodiment of professional and practical. The teaching mode of this module can be relatively flexible, it can be used in a discussion or two-way teaching, or it can be used in the mathematical application of a professional technical problem, and the task of teaching could be undertook by professional teachers. This interdisciplinary teaching mode is very helpful for students' thinking mode and innovative ability, and as a new attempt in accordance with the needs of training applied talents, mainly including linear algebra, probability statistics and so on.

The Thematic module. Mainly including the calculation method, the application of mathematical software, and the establishment of the model, through the modern education technology to reflect the application of mathematics in the project. The mathematics experiment includes basic experiment and comprehensive experiment. The purpose of the basic experiment is to study the use of mathematical software to understand the concepts in mathematics, and grasp the idea of mathematical calculation. The calculation method of the comprehensive experiment is to learn to use mathematical knowledge, and learn the whole process of mathematical modeling, and cultivate the ability of solve practical problems, so as to improve the comprehensive quality of students.

$$
\text { College Mathematics Curriculum System }\left\{\begin{array}{l}
\text { Foundation module }\left\{\begin{array}{c}
\text { Limit and continuity } \\
\text { Differential calculus } \\
\text { Integral calculus }
\end{array}\right. \\
\text { Application module }\left\{\begin{array}{c}
\text { Linear algebra } \\
\text { Probability statistics }
\end{array}\right. \\
\text { Thematic module - Computer mathematics experiment }
\end{array}\right.
$$




\section{Set the goal of College Mathematics Course}

Mathematics teaching, not only includes the knowledge teaching, but also includes the teaching to the student mathematics skill and the mathematics thought method. The ways to cultivate the thinking method and skill, are to allow students to participate in mathematical activities, feeling, experience and discovery, so that students have a positive emotional experience, stimulate their interests in learning, induce their inspiration of innovation .Therefore the scientific curriculum goal should include three levels : knowledge and skill, process and method, emotion and value.

Understand the background of mathematical concepts, and the nature of the concepts and conclusions, so as to understand the mathematical ideas and methods, and use the relevant mathematical conclusions to solve the production problems. Students will research activities, and experience the process of mathematical discovery and creation through autonomous learning.

Improve the ability of mathematical operation, combination of number and shape, logical thinking, basic tool using, and practical application ability so as to improve the ability of students of using mathematical methods to analyze problems and solve problems.

Develop innovative awareness, cultivate good mathematical literacy, and improve the interest of learning mathematics, so as to form a scientific attitude towards learning.

\section{The content of the college mathematics curriculum has the characteristic of practice}

The preparation of teaching materials with practical characteristics. Textbooks plays an important role in school education, and it's the most important resource to realize the course goal and the most important resource in the classroom teaching, and also is an important carrier of the development of the students. The teaching materials used in the university mathematics courses of local application oriented universities should have the characteristics of practical education, and fully embody the principles of application for the purpose. In order to overcome the disadvantages of the present teaching difficulty, with less time, enable students to broaden their horizons, learn knowledge as much as possible, and improve their learning ability, so as to adapt to the professional positions, and the social demand for highly skilled personnel. So educators should compile textbooks more close to the actual, outstanding applications, as far as simple and practical.

Strengthen the background of mathematical knowledge. For example, in the calculus of relevant content, through the movement of change, the mathematical problems, economic life, show such as limit, continuous, derivative, differential, integral, integral background in the calculus basic concept, and by means of abstraction, leads to the concept of matrix operation naturally. Doing like this will not only help students understand the abstract definition, but also help students to form the correct mathematical concept of mathematics from the real life. In addition, starting from the statistical problems in economic activities, guide students to experience the whole process from the data collection to processing, from the use of resources and other practical problems, as well as the organization of linear programming content, all of these reflect the outstanding background and strengthen the application of the guiding ideology.

Appropriate to streamline the content. So as to deal with the relationship between elementary mathematics and higher mathematics. For example, "Set and Basic elementary function" has been part of school textbooks, in order to reduce duplication, we could delete some of the contents or reduce the integral part of the calculation in the appendix appropriately. For higher vocational students, master the simple integral calculations can dilute the approximate calculation, and for this kind of problem can be solved by computer. 
Maintain the systematic and scientific of textbooks, and dilute the theory moderately. The local colleges aims to cultivate applied talents, the mathematics curriculum belongs to applied science. Therefore, to try to keep the textbooks of systematic and scientific and dilute the theory moderately, while emphasize the intuitive and reduce the argument. For example, the second important limits in "two important limits", is the method of directly verify. In the teaching, the scientific calculator aided teaching of "continuous function on a closed interval in nature", "mean value theorem", "basic properties of definite integral," multivariate function differential method "of teaching content, can be explained by geometric intuition too. In this way, it will not only highlights the application of the teaching materials, but also can save the teaching time, so as to provide the necessary time for the new teaching content.

Combine with professional practice, highlight the application of teaching content. On the one hand, we should highlight the application in the selection of knowledge content. For example, we should integrate all kinds of methods before to make the decision of the derivative method, especially in the derivative function of two variables, the operation should weaken the function of implicit. The derivation of implicit function and compound function both could use unary function derivation to solve, the curriculum should focus on mastering the basic calculation method of first derivative, and strengthen the application of derivative to solve the practical problems of the case. On the other hand, highlight the application in the selection of cases and exercises. In the examples and exercises, On the other hand, to highlight the application in the selection of cases and exercises. In the examples and exercises, we should choose some practical problems, and problems involving professional knowledge. Thus students can not only enhance the understanding of mathematical knowledge and mastery level, while improve the ability of solving problems, but also can enhance the mathematics and social life, improve the application ability and consciousness to solve practical problems, such as the optimization problem of the maximum profit, minimum cost, minimum materials, the best choice, the shortest line and other economic issues in the profit, production, cost, benefit in the daily life of the installment, insurance, lottery, savings and other issues. Through the examples and exercises, the goal to strengthen the consolidation of basic knowledge and basic methods, and strengthen the training of outstanding mathematics application ability will be achieved.

Case: The marginal revenue of a product known to produce a product is $R^{\prime}(q)=100-2 q$ (yuan/unit), to solve the production of 40 units of total income and average income, and seek to increase production of 10 units of the total revenue increase.

Answer: The total income from the output of a known product is $R(q)=\int_{0}^{q} R^{\prime}(q) d q$, directly get the answer $R(40)=\int_{0}^{40}(100-2 q) d q=\left.\left(100 q-q^{2}\right)\right|_{0} ^{40}=2400($ yuan $)$

The average income is $\frac{R(40)}{40}=\frac{2400}{40}=60($ yuan $)$

So the production of 40 units after the increase in the production of 10 units, the total income of the increase is: 


$$
\Delta R=R(50)-R(40)=\int_{40}^{50} R^{\prime}(q) d q=\int_{40}^{50}(100-2 q) d q=\left.\left(100 q-q^{2}\right)\right|_{40} ^{50}=100(\text { yuan })
$$

\section{Acknowledgement}

The teaching project of Nanjing Xiaozhuang University: Research on "university mathematics" practical teaching under the goal of training applied talents stage result. The project of reforming and developing significant and important problems during The 13th Five-year of Nanjing Xiaozhuang University: Research on "university mathematics" practical teaching under the goal of training applied talents in local undergraduate colleges and universities (2016XZGJ07) stage result. The sub-project of the Twelfth Five-year plan key project "Research on teachers' professional development" of National Teacher Research Fund of China: Research on "university mathematics" practical teaching (GJS1523125) stage result.

\section{Reference}

[1] Wu Zhihui, On the four philosophical views of curriculum globalization, Journal of Northeast Normal University: Philosophy and Social Sciences, vol.15, 2007.

[2] Guo Yuanxiang, The shift of curriculum view, Curriculum, Teaching Material and Method, vol.6, 2001. 